\title{
Abortion Experiences of Unmarried Young Women In India: Evidence from a Facility-Based Study In Bihar and Jharkhand
}

\author{
By Shveta \\ Kalyanwala, \\ A. J. Francis \\ Zavier, Shireen \\ Jejeebhoy and \\ Rajesh Kumar
}

Shveta Kalyanwala is senior program officer, A.J. Francis Zavier is program officer, Shireen Jejeebhoy is senior associate and Rajesh Kumar is assistant program officerall at the Population Council, New Delhi.

CONTEXT: Little is known about the experiences of unmarried young women in India who seek to terminate an unintended pregnancy.

METHODS: A survey was conducted among 549 unmarried women aged 15-24 who had obtained an abortion in 2007-2008 at one of 16 clinics run by the nongovernmental organization Janani in the states of Bihar and Jharkhand. Differences in background characteristics, and in obstacles to obtaining an abortion, between those who had an abortion in the first trimester and those who did so in the second trimester were compared, and logistic regression analysis identified associations between these factors and obtaining a second-trimester abortion.

RESULTS: Eighty-three percent of women realized they were pregnant within the first two months of their pregnancy, and $91 \%$ within the first trimester. Eighty-four percent decided before the end of the first trimester to have an abortion, but only $75 \%$ obtained one in this period. One in six participants said that pregnancy had resulted from a nonconsensual sexual encounter, and such reports were more frequent among those who obtained a second-trimester abortion. Women who were older or who had more schooling had a decreased likelihood of having a second-trimester abortion (odds ratios, 0.9 each), whereas those who lived in rural areas, those who did not receive full support from their partners and those who reported a forced encounter had an increased likelihood of having a late abortion (2.3-4.1).

CONCLUSIONS: Sex education programs that highlight the importance of recognizing a pregnancy early in gestation, and of obtaining an early abortion if a pregnancy is unwanted, are needed for unmarried young women and men. International Perspectives on Sexual and Reproductive Health, 2010, 36(2):62-71

Premarital sex is widely discouraged in India, particularly for young women, yet there is evidence that significant minorities of young men and women have engaged in sex before marriage. In a recent survey of youth aged 15-24 in six states, $15 \%$ of men and $4 \%$ of women reported having had premarital sex. ${ }^{1,2}$ A review of a number of less representative studies found rates of 15-30\% among young men and $1-10 \%$ among young women. ${ }^{3}$ Evidence also suggests that sexually active unmarried youth rarely or inconsistently use contraceptives, which exposes many young women to the risks of unintended pregnancy and abortion. ${ }^{2,4}$

Although evidence is sparse, in this conservative setting in which pregnancy among unmarried women is extremely stigmatized, such unintended pregnancies are almost always terminated. ${ }^{4,5}$ A better understanding of the contexts of abortion among unmarried youth-and their experiences in obtaining abortion services-is clearly needed to design programs that enable unmarried adolescents to exercise their right to safe abortion and so avoid the potentially adverse health consequences of an unsafe abortion. This descriptive, exploratory study examines the abortion-related experiences of unmarried women aged 15-24 who terminated an unintended pregnancy in 2007-2008 at clinics in the states of Bihar and Jharkhand in northern India.

\section{BACKGROUND}

In 2001, there were 219 million youth aged 15-24 in India, representing $21 \%$ of the population. ${ }^{6}$ Marriage continues to occur early for young women: The proportion of 20-24year-olds who had married before turning 18 declined from 50\% in 1998-1999 to 47\% in 2005-2006. ${ }^{7}$ By age 25 , almost all Indian women are married; indeed, only $6 \%$ of those aged 25-29 had not married by their 25th birthday. ${ }^{7}$ Moreover, most marriages are arranged by parents; for example, a study in six Indian states found that $94 \%$ of married young women reported such arrangements. ${ }^{8}$ Early childbearing among young women is also common: About one in six 15-19-year-olds had already given birth or become pregnant, and about half of India's total fertility rate was attributable to those aged $15-24 .^{7}$

The 1971 Medical Termination of Pregnancy Act made abortion legal for women under a wide range of conditions, ${ }^{9}$ and medication abortion has been available in India since 2002. ${ }^{10}$ Unmarried women are legally entitled to receive abortion services, although those younger than 18 must have their guardian's consent. ${ }^{9}$ Community-based studies have not been able to obtain reliable information about unintended pregnancy and abortion among unmarried youth, but in a recent study of unmarried college students, $9 \%$ of sexually experienced females reported an unintended pregnancy and $17 \%$ of sexually experienced males reported that 
they had ever impregnated a partner; all of these pregnancies were reported to have been terminated. ${ }^{4}$

Few hospital-based studies of unmarried women have been conducted over the last decade, ${ }^{11,12}$ but given the small proportion of women who remain unmarried by age 25 , it can be assumed that the overwhelming majority of unmarried women are indeed young. Studies from the 1970s and 1980s suggested that unmarried (mostly young) women constituted $20-30 \%$ of all clients seeking abortion, ${ }^{13-16}$ a pattern observed in both rural ${ }^{13}$ and urban areas. ${ }^{16-18}$ In addition, at least half of the unmarried women seeking abortions were younger than $20 .{ }^{19}$ Several studies have confirmed, moreover, that unmarried adolescents and young women are a highly vulnerable groupfor example, many sought an abortion in their second trimester. ${ }^{11-13,16-21}$ Indeed, in a study that compared married and unmarried abortion seekers, $59 \%$ of unmarried adolescents, compared with $26 \%$ of their married counterparts, underwent second-trimester abortions. ${ }^{17}$ According to another study, the mean gestation at termination was nine weeks for married women and 14 weeks for unmarried women. ${ }^{22}$

Facility-based studies have found that unmarried (mostly young) abortion seekers are more likely than married abortion seekers to be illiterate or poorly educated and to belong to a lower socioeconomic group. ${ }^{23-25}$ Moreover, the pregnancies of a significant minority of unmarried abortion seekers had resulted from forced sexual encounters, sometimes with a family member. 5,20,21

Decision making is one of the least studied aspects of abortion-seeking behavior, and the sparse evidence suggests that for unmarried young women, the mother is usually the primary decision maker regarding abortion, with the partner and the father being far less involved. 5,11,18,20 Indeed, few partners were found to assist young women in obtaining an abortion, and the pregnancy was often hidden from the father for fear of physical violence.

Stigma is another major factor in getting an abortion: Pregnancy among the unmarried is so stigmatized that it is perceived to ruin a family's reputation, and in extreme cases, suicide is perceived at the family and societal levels as an option for pregnant, unmarried young women. ${ }^{5,20}$ In one study, 24\% of 500 unmarried adolescent abortion seekers reported that their parents had taken punitive measures, including beating or starving them for prolonged periods. ${ }^{18}$

Given all of these obstacles, young women experience delays in recognizing pregnancy, obtaining their family's permission, accumulating resources to pay for the abortion and choosing a provider. ${ }^{11}$ Indeed, the initial response to a missed menstrual period may be an attempt to "bring on" the delayed period with medicine from a local chemist or with home remedies (e.g., eating unripe papaya or drinking a brew made from peppercorn, papaya seeds and coffee), ${ }^{11}$ thereby further delaying the abortion. Some evidence suggests that adolescents are also more likely than older women to seek repeat abortions. ${ }^{18,19,26}$
TABLE 1. Demographic and reproductive health indicators in Bihar and Jharkhand, India

Indicator

Demographic

Total population (000s)

Urban

Belong to scheduled tribe

Belong to scheduled caste

Below poverty line

Total fertility rate

India

Bihar

Jharkhand

Young women (age-group)

Literate (15-24)

Married by age 18 (20-24)

Have given birth/been pregnant (15-19)

Have had premarital sex (15-24)

$1,028,610$

82,999

26,946

10.5

22.2

27.8
8.2

16.2

27.5

2.7

0.9
15.7

15.7
41.4

26.3

11.8

40.3

4.0

3.3

Reproductive health

Unmet need for contraception (15-49)

Deliveries in an institution

Deliveries by skilled personnel

No. of institutions approved to provide abortionst

67.7

47.4

16.0

3.5

42.8

69.0

25.0

2.6

50.3

63.2

27.5

6.7

†Approved by Mar. 31, 2006. $\neq$ Combined figure for Bihar and Jharkhand. Notes: All figures are percentages unless otherwise indicated. na=not available. Sources: Poverty —India Planning Commission, Poverty estimates for 2004-05,March 2007, <http://planningcommission.gov.in/news/prmar07.pdf >, accessed Aug. 10,2009. Total fertility rate-reference 7. Other demographic data-reference 6. Literacy —Office of the Registrar General and Census Commissioner, Social and Cultural Tables, Series C-8, 2001, New Delhi: Office of the Registrar General and Census Commissioner, 2001. Married by age 18-reference 7; International Institute for Population Sciences (IIPS) and Macro International, National Family Health Survey (NFHS-3), 2005-06, Bihar, India, and National Family Health Survey (NFHS-3), 2005-06, Jharkhand, India, Mumbai: IIPS, 2008. Adolescent birth or pregnancy-reference 7.Premarital sex-references 27 and 28. Institutions approved-Ministry of Health and Family Welfare (MOHFW), Family Welfare Statistics in India-2006, New Delhi: MOHFW, 2007, <http:// mohfw.nic.in/dofw\%20website/FWSII\%20-\%202006/BOOK.htm>, accessed July 28,2008. Other reproductive health data-reference 7 .

\section{Study Setting}

Bihar and Jharkhand are neighboring states in northern India; Jharkhand was part of Bihar until 2000, when it became a separate state. Bihar is the third largest state by population (83 million), and Jharkhand ranks 13 th (27 million). ${ }^{6}$ The majority of socioeconomic indicators in the two states are similar (Table 1). Compared to the country as a whole, both states have a higher proportion of their population living below the poverty line (40-41\% vs. $28 \%$ ), a lower proportion residing in urban areas (11-22\% vs. $28 \%$ ) and a higher fertility rate (3.3-4.0 vs. 2.7 births per woman). Jharkhand has a proportionally larger population belonging to scheduled tribes than Bihar (26\% vs. $1 \%$; national average, $8 \%$ ), a fact taken into consideration in the formation of Jharkhand, as well as a proportionally smaller population belonging to scheduled castes ( $12 \%$ vs. 16\%; national average, 16\%).*

Other indicators also suggest that young women in Bihar and Jharkhand are worse off than those in other states. Compared with all Indian women in the corresponding agegroups, women aged 15-24 in Bihar and Jharkhand report lower literacy rates (43-50\% vs. 68\%), those aged 20-24 are more likely to have married by age 18 (63-69\% vs. 47\%) and those aged 15-19 are more likely to have experienced a pregnancy (25-28\% vs. 16\%). Furthermore, in both states,

*Scheduled castes include caste groups that have traditionally occupied a low status in Indian society; scheduled tribes include tribal populations that are characterized by their own language, customs and traditions according to Government of India notification. 
similar proportions of women aged 15-24 have had premarital sex ( $3-7 \%$ vs. $4 \%$ in a study of six states); only $5 \%$ of sexually experienced women in this age-group reported consistent condom use. , $27,28^{2}$

Use of health services is more limited in Bihar and Jharkhand than in India in general. For example, the proportion of women aged 15-49 with an unmet need for contraception was higher in these states than in India overall ( $23 \%$ each vs. $13 \%$ ), the proportion of deliveries that occurred at an institution was lower (18-20\% vs. 39\%) and the proportion of deliveries that were performed by a skilled attendant was lower (28-29\% vs. 47\%). Moreover, the two states contain just 116 of the 11,636 facilities approved to provide abortion services.

The study was conducted between November 2007 and December 2008 at 16 clinics run by Janani, a nongovernmental organization that is among the largest public-private networks delivering family planning and reproductive health care in India. Janani is affiliated with DKT International, which operates in 14 countries to promote reproductive health and HIV and AIDS prevention through social marketing. Janani's clinics are certified under the Medical Termination of Pregnancy Act, and each clinic employs at least one doctor who is registered to provide abortions. Although Janani charges a nominal fee, ${ }^{*}$ large numbers of poor women prefer its clinics to other private health facilities or government clinics because they offer reliable, confidential and high-quality services, and have no hidden costs (e.g., for drugs or tests). As a result, Janani clinics perform a large proportion of all abortions in Bihar and Jharkhand.

\section{DATA AND METHODS Sample}

We conducted a facility-based rather than a communitybased study for several reasons. First, because abortion is relatively uncommon and because pregnancy among the unmarried is highly stigmatized in India, community survey-based abortion data greatly underestimate the incidence of abortion among unmarried young women, and even a subnational study of youth in six states failed to obtain reliable information. ${ }^{2}$ In contrast, according to earlier studies, ${ }^{11,15,16,23}$ unmarried young women were willing to reveal their marital status in facility settings, and we assumed that patients attending Janani clinics-which have a reputation of maintaining client confidentiality-would thus be more likely to accurately report their marital status if asked. Second, by locating the study in clinics, we could provide access to counseling services for respondents who had had difficulty either getting an abortion or describing their experience. Finally, the clinical settings from which the sample was drawn were quite diverseranging from large urban areas to small towns, and serving both urban and rural residents.

We focused on unmarried women aged 15-24 who had

*At the time of the survey, a medication abortion cost 199 rupees (Rs. US\$4), a first-trimester surgical abortion cost Rs. 399 (US\$9) and a secondtrimester surgical abortion cost Rs. 799 (US\$18). not had a previous pregnancy or who had terminated any previous pregnancies (in a few cases, pregnancy had not resulted in a live birth). As mentioned earlier, childbirth outside of marriage is extremely rare in India; in addition, given the pressure on young women to prove their fertility as soon as possible after marriage, evidence suggests that relatively few young married women would seek to terminate their first pregnancy. ${ }^{29,30}$ Moreover, because staff at Janani clinics do not ask clients about their marital status, our strategy of recruiting women who had not had a previous pregnancy or birth ensured that no young women were identified as unmarried or stigmatized on the basis of marital status, while at the same time it maximized our chances of recruiting the unmarried. Yet we recognized that some unmarried women seeking an abortion would attempt to conceal their marital status, so interviewers were trained to build rapport with respondents, and questions about marital status were asked in the middle of interviews. Furthermore, at the conclusion of interviews, all respondents were asked to record their marital status anonymously on a form that they returned to the interviewer in a sealed (but linked) envelope.

\section{Measures}

Survey questions explored respondents' abortion experiences and the circumstances of their pregnancy. Women were asked when they had realized that they were pregnant, when they had decided to get an abortion and when they had actually had the abortion (categories were in the first, second or third month of pregnancy, or after the first trimester); they also identified who was involved in their getting pregnant (boyfriend or fiancé, a family member, a neighbor, an acquaintance or stranger, a colleague, or a teacher or employer). Because we hypothesized that a delay in getting an abortion may be related to the nature of the sexual encounter resulting in pregnancy, women were asked whether relations were consensual, or whether they had been persuaded to have sex or had been forced to do so. Women were also asked whether they had made previous unsuccessful attempts to terminate the pregnancy, and if so, what type of provider had been involved (a physician, an unqualified individual such as a homeopath or a nurse, a chemist or the woman herself) and the method used (medication, surgical, other or none).

Other factors that might inhibit or facilitate prompt care-seeking were also assessed. One was the nature of the support that women received from their partner, mother, other family member or friend. All respondents were asked whether they had confided in someone about the unwanted pregnancy, and if so, in whom. (Respondents were also asked about cases in which individuals had learned about the pregnancy from someone in whom the respondent had confided.) Those who reported that they had confided in their partner were asked whether he had provided emotional support and financial support, and whether he had accompanied them to the clinic. Women who said they had confided in anyone else were asked 
whether that person had provided any support (without specifying emotional or financial), and whether that person had accompanied them to the clinic for the abortion procedure. From these responses, we determined the percentage of women who had both received support from and were accompanied to the facility by their partner, a family member or a friend.

Participants were also asked whether they were awareprior to getting pregnant-that abortion is legal, whether they were involved in the decision to have an abortion (either alone or with others) and whether they chose the facility because of its reputation for protecting clients' confidentiality. Furthermore, we examined women's perceptions about the quality of care obtained from the Janani clinic and from any other provider from whom they had sought an abortion.

Finally, because respondents' social and demographic characteristics could have influenced their abortionseeking behavior, information was collected on women's age, residence (in an urban or rural area, and in Bihar or Jharkhand), education (years of schooling and whether currently in school), whether respondents had worked for pay in the last year and whether they lived at least 1.5 hours from a clinic.

\section{Protocol}

Following their abortion, respondents were interviewed at a time and place of their choosing; most interviews took place in the clinic before discharge. Consent was sought from all eligible women at two points in time. First, prior to their abortion, women were informed about the study's objectives, procedures and measures for ensuring privacy, as well as the rights of respondents, and were invited to participate. Then, before the scheduled interview, those who had consented earlier were asked again to provide consent, and only those who consented at both times were enrolled in the study and interviewed. Although the study also included in-depth interviews of selected survey respondents, those findings are not included here. Each interview lasted about 30 minutes.

Overall, 549 unmarried and 246 married young women were recruited, and those who said they were married were excluded from the analysis. Only six women refused to participate.

\section{Analysis}

Chi-square and t tests were conducted to identify differences in a number of variables between women who had a first-trimester abortion and those who had one in the second trimester. Multivariate logistic regression analysis was then used to identify the key factors associated with whether women obtained second- rather than firsttrimester abortions; explanatory variables included social and demographic factors (age, education, employment status, rural-urban residence and state of residence) and factors that may have acted as obstacles to obtaining a firsttrimester abortion (previous attempts to terminate the
TABLE 2. Social and demographic characteristics of unmarried women aged 15-24 who obtained an abortion at a Janani clinic, Bihar and Jharkhand, India, 2008

Characteristic All

PERCENTAGE DISTRIBUTIONS

Age

15-17

18-19

$20-24$

Residence

Urban

State of residence

Bihar

Jharkhand

Total

100.0

MEANS AND PERCENTAGES

Mean age

Mean no. of yrs. of schooling

Currently in school

Worked for pay in last 12 mos.

Lived $\geq 1.5$ hrs. from clinic

pregnancy, lack of partner support, lack of prior knowledge about the legality of abortion, whether the pregnancy had resulted from forced sex and whether confidentiality had played a key role in facility selection).

\section{RESULTS}

\section{Sample Characteristics}

Young unmarried women who sought abortion services at Janani clinics during the study period had characteristics similar to those of unmarried women aged 15-24 in urban areas of Bihar and Jharkhand, according to data obtained from two state-level studies. ${ }^{27,28}$ In the one substantial difference, half the respondents were younger than 20 (Table 2), compared with $76-78 \%$ of women in the statelevel studies. Seventy-eight percent resided in urban areas, and 22\% in rural areas; $65 \%$ lived in Bihar, and 35\% in Jharkhand. On average, participants had completed nine years of schooling, and 55\% were currently in school. Twenty-one percent had worked for pay or other compensation in the last year, and 26\% lived at least 1.5 hours from a Janani facility.

\section{Timing of Abortion-Related Events}

While $83 \%$ of women realized that they were pregnant within the first two months of pregnancy, and 91\% within the first trimester, $9 \%$ did not realize it until the second trimester (Table 3, page 66). Common reactions to the pregnancy were fear, anxiety and guilt, which were reported by $70 \%, 80 \%$ and $18 \%$, respectively, of respondents (not shown). Once they recognized they were pregnant, women had to decide whether to have an abortion: Eighty-four percent made up their mind in the first trimester; the remainder did not decide until they were in the second trimester. Although 75\% of respondents obtained an abortion in the first trimester, 25\% had an abor- 
TABLE 3. Timing of women's realization they were pregnant, decision to get an abortion and the performance of the abortion, by trimester of pregnancy

Variable

All $\mid$ First

$(\mathrm{N}=549) \quad$ trimester trimester

$(\mathrm{N}=410) \quad(\mathrm{N}=139)$

Realized they were pregnant

Month***

1

2

3

$\geq 4$

Mean no. of mos.***

2.0

Decided to get abortion

Month ${ }^{* * *}, \dagger$

1

3

$\geq 4$

Mean no. of mos.***

Obtained abortion

Month

1

2

3

$\geq 4$

Mean no. of mos.***

*** $\mathrm{p}<$.001. Information missing for one woman who had a second-trimester abortion. Notes: Percentages may not total 100.0 because of missing cases. na=not applicable.

tion in the second trimester. On average, women realized they were pregnant two months into their pregnancy, decided to have an abortion at 2.4 months and obtained an abortion at 2.9 months, that is, almost into the second trimester.

As expected, delayed recognition of pregnancy was associated with having a second-trimester abortion. Ninetysix percent of women who terminated their pregnancy in the first trimester had realized they were pregnant within the first two months, compared with $43 \%$ of those who had an abortion in the second trimester. Indeed, while those who had a first-trimester abortion had recognized

\begin{tabular}{|c|c|c|c|}
\hline Circumstance & All & $\begin{array}{l}\text { First } \\
\text { trimester }\end{array}$ & $\begin{array}{l}\text { Second } \\
\text { trimester }\end{array}$ \\
\hline \multicolumn{4}{|l|}{ Person involved ${ }^{* * *}$} \\
\hline Boyfriend/fiancé & 76.5 & 84.1 & 54.0 \\
\hline Family member & 9.1 & 7.3 & 14.4 \\
\hline Neighbor & 5.8 & 2.7 & 15.1 \\
\hline Acquaintance/stranger & 5.5 & 3.4 & 11.5 \\
\hline Colleague & 1.5 & 1.5 & 1.4 \\
\hline Teacher/employer & 1.6 & 1.0 & 3.6 \\
\hline \multicolumn{4}{|l|}{ Consensuality*** } \\
\hline Both willing & 68.1 & 75.4 & 46.8 \\
\hline Woman persuaded & 14.4 & 13.2 & 18.0 \\
\hline Woman forced & 17.5 & 11.5 & 35.3 \\
\hline Total & 100.0 & 100.0 & 100.0 \\
\hline
\end{tabular}

the pregnancy at an average of 1.6 months, those who had a second-trimester abortion had recognized it much later, at 3.1 months, on average.

Decision-making delays were correlated with when an abortion was obtained: Twenty percent of women who had a second-trimester abortion made the decision within two months of getting pregnant, whereas 91\% of those who had a first-trimester abortion decided during this period. On average, those who had a second-trimester abortion made the decision two months later than did those who had one in the first trimester (3.9 vs. 1.9 months). First-trimester abortions occurred at an average of 2.2 months' gestation, while second-trimester abortions were performed at about 4.7 months.

Several demographic characteristics were correlated with having a second-trimester abortion (not shown). Compared with women who had an abortion in the first trimester, those who had one in the second trimester were younger (18 vs. 20), less educated (seven vs. 10 years of schooling, on average), less likely to reside in urban areas ( $53 \%$ vs. $87 \%$ ) and more likely to live at least 1.5 hours from a Janani facility (45\% versus 20\%).

\section{Circumstances of Pregnancy}

Three-fourths of participants reported that their pregnancy had resulted from sexual relations with a boyfriend or fiancé (Table 4). The remaining pregnancies resulted from relations with a family member (9\%), a neighbor (6\%), an acquaintance or stranger (6\%), or a colleague, teacher or employer (3\%). Compared with second-trimester abortions, first-trimester abortions were more likely to have resulted from relations with a boyfriend or fiancé (84\% vs. $54 \%$ ), and less likely to have resulted from relations with a family member ( $7 \%$ vs. 14\%), neighbor (3\% vs. $15 \%$ ), or acquaintance or stranger (3\% vs. $12 \%$ ).

Two-thirds of participants said that pregnancy occurred as a result of consensual sexual relations, while one in six said that the sexual encounter had been forced and one in seven reported that their partner had persuaded them to have sex. Those who had a second-trimester abortion were more likely than those who had a first-trimester abortion to report that the pregnancy had resulted from forced sex ( $35 \%$ vs. $12 \%$ ).

The proportion of women who had become pregnant through forced sex varied with the type of partner who had impregnated them (not shown), from $4 \%$ of women who had become pregnant by a boyfriend or fiancé to much larger proportions of those who had become pregnant by a neighbor (44\%) or a family member (54\%). Meanwhile, $90 \%$ of women whose partner was an acquaintance or stranger said the encounter was forced.

\section{Previous Abortion Attempts}

Prior to having an abortion at a Janani clinic, a third of participants had made an unsuccessful attempt to terminate their pregnancy (Table 5). Overall, 5\% of women had made two or more previous attempts $-4 \%$ of those who 
subsequently had a first-trimester abortion and 9\% of those who had a second-trimester procedure. Unfortunately, data were not collected on the interval between recognition of the pregnancy and each unsuccessful attempt, nor between the last unsuccessful attempt and their abortion at a Janani facility.

When women were asked what type of provider they had used in a previous attempt (multiple responses were allowed), one in six said they had used a physician (some of whom may not have been certified to provide abortions), and a similar proportion reported having used an unqualified provider (e.g., homeopath, rural medical practitioner or traditional birth attendant). Three-fourths had obtained medication from chemists, who are currently not permitted to dispense abortion drugs without a prescription. Finally, fewer than one in 10 reported making the attempt on their own or with the help of a family member, partner or friend. The provider type used by women differed by trimester of abortion: Compared with women who had a second-trimester abortion, those who had a first-trimester procedure were more likely to have sought medication from a chemist ( $83 \%$ vs. 63\%), and less likely to have sought an abortion from a physician (12\% vs. $30 \%$ ) or an unqualified provider ( $11 \%$ vs. $30 \%$ ).

Women were also asked about the methods they had used in previous attempts (and some gave multiple responses). Eighty-three percent had taken oral medication, and nearly all of these women had obtained it from a chemist (not shown). * Three percent had relied on surgical intervention, $10 \%$ had used herbs, instruments or homemade concoctions, and 9\% reported that the provider had refused to intervene, for a variety of reasons: The provider had refused services, often because the pregnancy was relatively advanced and the provider was either unqualified or uncertified to perform second-trimester abortions; the provider had offered only counseling or referral; the client was unable to pay the fee; or the client perceived that the provider would not provide high-quality services. Women who had a first-trimester abortion were more likely than those who had a second-trimester abortion to have first attempted to terminate their pregnancy by using medication ( $86 \%$ vs. $70 \%$ ), and were less likely to have tried surgical intervention ( $1 \% \mathrm{vs.} 8 \%$ ) or other methods (e.g., inserting herbs or instruments, or consuming home remedies; $7 \%$ vs. $23 \%$ ) or to have used no method (6\% vs. 20\%).

\section{Support from Partners and Others}

All participants had confided in at least one person about their unintended pregnancy, and the overwhelming majority said they had received support (not shown). In some instances, financial support was received from someone in whom a participant had not confided (notably the father), but who had learned about the pregnancy. Among all women, $77 \%$ had confided in their sexual partner, and $78 \%$ reported that their partner knew about the pregnancy (Table 6, page 68). Overall, 92\% of women whose part-
TABLE 5. Percentage of women who made unsuccessful attempts to terminate their pregnancy, by trimester of pregnancy, according to the provider and method used

\begin{tabular}{|c|c|c|c|}
\hline Variable & All & $\begin{array}{l}\text { First } \\
\text { trimester }\end{array}$ & $\begin{array}{l}\text { Second } \\
\text { trimester }\end{array}$ \\
\hline Previous attempts & $(\mathrm{N}=549)$ & $(\mathrm{N}=410)$ & $(\mathrm{N}=139)$ \\
\hline Any & 32.6 & 33.9 & 28.8 \\
\hline$\geq 2^{*}$ & 5.1 & 3.9 & 8.6 \\
\hline Providert & $(\mathrm{N}=179)$ & $(\mathrm{N}=139)$ & $(\mathrm{N}=40)$ \\
\hline Physician ${ }^{* *}, \neq$ & 15.6 & 11.5 & 30.0 \\
\hline Unqualified provider**,§ & 15.1 & 10.8 & 30.0 \\
\hline Chemist $^{* *}$ & 78.2 & 82.7 & 62.5 \\
\hline Self t† & 6.7 & 5.0 & 12.5 \\
\hline Methodt & $(\mathrm{N}=179)$ & $(\mathrm{N}=139)$ & $(\mathrm{N}=40)$ \\
\hline Medication* & 82.7 & 86.3 & 70.0 \\
\hline Surgical* & 2.8 & 1.4 & 7.5 \\
\hline Other**, & 10.1 & 6.5 & 22.5 \\
\hline None $e^{* *}, \S \S$ & 8.9 & 5.8 & 20.0 \\
\hline
\end{tabular}

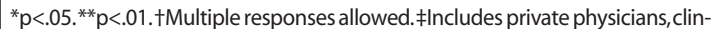
ic physicians and government doctors. §Includes homeopaths, rural medical practitioners, traditional birth attendants, nurses and auxiliary nurse midwives. t+Includes all those who attempted an abortion by inserting herbs or sticks or by consuming homemade concoctions, with or without the help of a family member, partner or friend. \#‡Includes herbs, instruments and concoctions. $\S \S$ Includes cases in which the provider refused services, the provider offered only counseling or referral, the provider was unqualified to perform secondtrimester abortions, the client was unable to pay the fee or the client perceived that the provider would not provide quality services.

ners knew about their situation indicated that they had received at least one type of support; $86 \%$ received emotional support, and $51 \%$ received financial support. More than seven in 10 reported that their partner had accompanied them to the Janani clinic, and a similar proportion indicated that their partner had both provided support (emotional or financial) and accompanied them.

Smaller proportions of women reported that they had either confided in individuals other than partners or that others had learned about their pregnancy: Thirty-two percent cited their mother, 28\% another female relative, 19\% a male relative (including fathers) and $21 \%$ a friend. Large proportions of mothers, other female relatives and friends who had been confided in or who learned about the pregnancy provided some support (70-85\%), but smaller proportions of these subgroups accompanied respondents to clinics (45\%-72\%) or both provided support and accompanied them (31-59\%). Some women reported that although they had not confided in their father or a male relative about the pregnancy, their mother or a female relative in whom they had confided had informed the male relative. Overall, among women who said that a male relative knew about their situation, 51\% received support from such relatives, $77 \%$ were accompanied to the clinic by them and $31 \%$ both received support and were accompanied.

Young women who obtained an abortion in the first versus the second trimester reported different levels of sup-

*Numerous ayurvedic, homeopathic and other medicines are available at chemist shops, but we did not assess which were used. Nor did we ascertain whether unmarried women used a mifepristone-misoprostol combination that is readily available over the counter (source: Ganatra B et al., Availability of medical abortion pills and the role of chemists: a study from Bihar and Jharkhand, India, Reproductive Health Matters, 2005, 13(26):65-74). 
TABLE 6. Percentage of women who confided in their partner or others about their unwanted pregnancy, and percentage reporting support from these individuals for obtaining an abortion, by type of support received, all according to trimester of abortion

Variable

All $\quad$ First Second

\begin{tabular}{ll|ll} 
& trimester & trimester \\
\hline CONFIDED IN & $(\mathrm{N}=549)$ & $(\mathrm{N}=410)$ & $(\mathrm{N}=139)$
\end{tabular}

\begin{tabular}{ll|ll} 
Partner*** & 77.4 & 84.2 & 57.6
\end{tabular}

Mother***

$\begin{array}{lllll}\text { Other female relative }^{* * *} & 25.3 & 21.5 & 36.7\end{array}$

\begin{tabular}{|ll|ll} 
Male relative (including father) $^{* *}$ & 10.6 & 8.1 & 18.0
\end{tabular}

Friend

CONFIDED IN/LEARNED

ABOUT PREGNANCY†

Partner***

Mother***

Other female relative*** 28.4

Male relative (including father) $* * * \quad 19.1$

Friend

\begin{tabular}{l|l}
20.8 & 21.0
\end{tabular}

SUPPORT‡

Partner

Provided support****

Emotional $^{* * *}$

Financial

Accompanied to clinic***

Provided support and

accompanied to clinic $^{* * *}$

Mother

Provided support

Accompanied to clinic**

Provided support and

accompanied to clinic

Other female relative

Provided support

Accompanied to clinic

Provided support and

accompanied to clinic

Male relative (including father)

Provided support

Accompanied to clinic

Provided support and accompanied to clinic

Friend

Provided support

Accompanied to clinic

Provided support and

accompanied to clinic

${ }^{* *} p<.01 .{ }^{* * *} p<.001$. Includes those who were confided in and those who learned about the pregnancy from someone in whom the respondent had confided. ¥Percentages based on the respective Ns. Note: Multiple responses allowed for the confided in and support measures.

port. Compared with those who had a second-trimester abortion, those who had a first-trimester abortion were more likely to have confided in their partner (84\% vs. $58 \%$ ). Nearly identical proportions reported that their partner knew about the pregnancy, and among these women, those who had a first-trimester abortion were more likely to have received support from their partner (95\% vs. $82 \%$ ), and the partner was more likely to have accompanied them to the clinic ( $78 \%$ vs. $48 \%$ ); these women were also more likely to have both received support from and been accompanied by their partner (76\% vs. $43 \%$ ). In contrast, women who had a second-trimester abortion were more likely than those who had one in the first trimester to have confided in their mother ( $51 \%$ vs. $21 \%$ ) or other female relative (37\% vs. $22 \%$ ); these differences were even greater among women whose mother or other female relative knew about the pregnancy (60\% vs. $22 \%$ and $46 \%$ vs. $22 \%$, respectively). Among women whose mothers were aware of their pregnancy, $82 \%$ of those who had a second-trimester abortion said that their mother accompanied them to the clinic, whereas this was reported by $62 \%$ of those who had an abortion in the first trimester. Finally, respondents who had a second-trimester abortion were more likely than those who had one in the first trimester to have confided in a male relative (18\% vs. $8 \%$ ), and this difference was even larger among those who reported that a male relative knew about their pregnancy (34\% vs. $14 \%$ ).

\section{Decision-Making Factors}

Only 22\% of respondents were aware, prior to becoming pregnant, that the procedure is legally available to unmarried women in India (not shown). Women were more likely to be aware of this if they had a high school education rather than less education ( $28 \%$ vs. $12 \%$ ), and if they had a first-trimester abortion rather than a second-trimester procedure ( $24 \%$ vs. $17 \%$ ). Four in five women were involved in deciding whether they would get an abortion, and those who had the procedure in the first trimester were more likely than those who had it in the second trimester to report such participation (86\% vs. 66\%). Among respondents who did not participate in the decision, threefourths said their parents had made the final decision.

While two-thirds of respondents said the reputation of the facility or provider was important in making their decision, 10\% mentioned providers' nonjudgmental attitudes. Half reported that they had chosen a Janani clinic, or had visited another facility or provider earlier, because it had a reputation for providing confidential services, or because a facility far from home reduced the chance of inadvertent disclosure. Women who had a second-trimester abortion were more likely than those who had a firsttrimester abortion to say that confidentiality was a critical factor in their selection of a clinic (64\% vs. $48 \%$ ).

\section{Delay Factors}

In regression analyses that controlled for social and demographic factors, as well as factors that may have acted as obstacles to obtaining a first-trimester abortion, older women and those with more years of schooling were less likely than younger women and those with less schooling, respectively, to have had a second-trimester abortion (odds ratios, 0.9 for each; Table 7). Compared with respondents who lived in urban neighborhoods of Bihar, those from rural areas of either Bihar or Jharkhand were more likely to have had a later abortion (2.5 and 4.1, respectively). Moreover, women who did not receive full support from their partner and those who reported that their pregnancy had resulted from a forced sexual en- 


\begin{tabular}{|c|c|}
\hline Characteristic & Odds ratio \\
\hline \multicolumn{2}{|l|}{ DEMOGRAPHIC } \\
\hline Age & $0.88(0.88-0.89)^{*}$ \\
\hline Yrs. of schooling & $0.92(0.92-0.93)^{* *}$ \\
\hline \multicolumn{2}{|l|}{ Currently working } \\
\hline No (ref) & 1.00 \\
\hline Yes & $0.98(0.96-1.00)$ \\
\hline \multicolumn{2}{|l|}{ Residence } \\
\hline Bihar urban (ref) & 1.00 \\
\hline Bihar rural & $2.54(2.49-2.60)^{* * *}$ \\
\hline Jharkhand urban & $1.49(1.46-1.52)$ \\
\hline Jharkhand rural & $4.07(3.98-4.16)^{* * *}$ \\
\hline \multicolumn{2}{|l|}{ OBSTACLESTO ABORTION } \\
\hline \multicolumn{2}{|l|}{ Previous attempts } \\
\hline $0-1$ (ref) & 1.00 \\
\hline$\geq 2$ & $2.17(2.10-2.23)$ \\
\hline \multicolumn{2}{|l|}{ Partner support† } \\
\hline Partner supported fully (ref) & 1.00 \\
\hline Partner did not support fully & $2.32(2.27-2.36)^{* *}$ \\
\hline Sexual encounter was forced & $3.73(3.66-3.81)^{* * *}$ \\
\hline \multicolumn{2}{|c|}{ Awareness that abortion is legal $\neq$} \\
\hline Yes (ref) & 1.00 \\
\hline No & $1.08(1.06-1.10)$ \\
\hline \multicolumn{2}{|c|}{ Facility chosen on basis of confidentiality } \\
\hline No (ref) & 1.00 \\
\hline Yes & $1.12(1.10-1.14)$ \\
\hline Constant & 2.31 \\
\hline$-2 L L$ & 490 \\
\hline$R^{2}$ & 0.32 \\
\hline \multicolumn{2}{|c|}{$\begin{array}{l}{ }^{*} \mathrm{p}<.05 .{ }^{* *} \mathrm{p}<.01 .{ }^{* * *} \mathrm{p}<.001 \text {. }+ \text { Full support included both emotional and } \mathrm{fi} \\
\text { nancial support. } \neq \text { Before getting pregnant, respondent was aware tha } \\
\text { abortion is legal for unmarried women. } \text { fChoice of facility was based or } \\
\text { whether providers had ensured patient confidentiality and whethe } \\
\text { facility was far from home (to avoid inadvertent disclosure). Notes } \\
\text { ref=reference category. } \mathrm{N}=549 \text {. }\end{array}$} \\
\hline
\end{tabular}

counter had higher odds of having had a second-trimester abortion than did women whose partner supported them fully (2.3 and 3.7, respectively). The other potential delay factors were not associated with having a secondtrimester abortion.

\section{DISCUSSION}

The experiences of unmarried young women who terminate an unintended pregnancy, and the pathways they follow in obtaining an abortion, have received little study in India. Our findings highlight several significant obstacles to obtaining a timely abortion. Young women's failure to promptly recognize that they are pregnant reflects a general lack of awareness that a missed period may indicate a pregnancy; in addition, a previous study found that just $35 \%$ of unmarried young women were aware that they could become pregnant at their first sexual intercourse, and only $23 \%$ were aware that pregnancy can occur midcycle. ${ }^{2}$ Moreover, while we found that one-third of unmarried young women in our sample had made at least one unsuccessful attempt to terminate an unintended preg- nancy, a recent study in rural areas of Maharashtra and Rajasthan found that just 18-19\% of married women aged 15-39 had made at least one unsuccessful attempt. ${ }^{31}$

One factor that is clearly associated with prompt abortion-seeking is the support of the partner. Whereas earlier studies had suggested that partner support in general may be lacking, 5,18,20 our findings showed that partners were the leading source of support for young women. Indeed, women whose partner did not fully support them were more likely than those whose partner gave both emotional and financial support to have had a secondtrimester abortion rather than one in the first trimester.

We also found that young women who confided in and were accompanied to the facility by their mother were more likely to obtain a second-trimester abortion than a first-trimester procedure, and this may be explained by how women seek assistance. For example, we hypothesize that young women are most likely to confide in their partner, and if he does not provide emotional or financial support, or if the respondent is not in a position to involve her partner (e.g., if the pregnancy resulted from a forced encounter), she would then turn to her mother, other family members or friends. Hence, women who had a supportive partner were more likely than others to have obtained a first-trimester abortion, whereas lack of partner supportand consequent reliance on the mother and othersdelayed the abortion-seeking process into the second trimester. It is notable that young women were reluctant to confide in their father or other male relatives, and that overall these family members were less likely to offer support than were partners, mothers, other female relatives or friends. This difference has also been found in previous studies, ${ }^{5,11}$ and is consistent with young women's fear of disclosing their pregnancy to family members.

\section{Limitations}

Because community-based studies in India have failed to provide reliable information on the abortion-seeking behavior of unmarried women, we opted for a facility-based study, yet this approach has limitations. Although our findings suggest that the social and demographic characteristics of abortion seekers were similar to those of unmarried, urban young women in these two states, we acknowledge that our results cannot be generalized to all young abortion seekers in Bihar and Jharkhand. In addition, the study was restricted to clients of a single nongovernmental organization provider, and therefore it excluded unmarried young women who sought abortion from government or private-sector facilities or from uncertified providers, as well as those who may have successfully terminated their pregnancy by taking a mifepristone-misoprostol combination that is available from chemists.

We also recognize that despite respondents' opportunity to report their marital status anonymously, some unmarried women may have concealed their status. Furthermore, because many respondents were interviewed shortly after their surgical procedure, we did not collect in- 
formation about a number of important issues, such as details of their decision-making process, earlier experiences in terminating a pregnancy, the type of oral medication taken and actions taken to avoid disclosure of their unintended pregnancy and subsequent abortion. Finally, because we focused on young women who had not had a previous pregnancy, or who had terminated any previous pregnancies, these findings are not representative of abortion seekers in general.

\section{Conclusions}

Our findings offer a number of directions for India's reproductive health programs. Sex education programs for both in-school and out-of-school young women should include information on the link between a missed period and an unintended pregnancy, the importance of obtaining an early abortion if the pregnancy is unwanted and the fact that both married and unmarried women are legally entitled to pregnancy termination services. Furthermore, because distance from abortion services proved to be a considerable obstacle to access, there is a critical need to expand access to abortion services and to improve them so that they are more youth-friendly and nonjudgmental. Increased attention should also be paid to improving communication between young women and their parents. Finally, and perhaps most important, findings on the central role of partners in influencing women's ability to obtain early abortion services highlight the need for programs for young men and women that foster more egalitarian gender attitudes and increased male responsibility regarding reproductive health.

\section{REFERENCES}

1. Santhya KG et al., Pre-marital sexual relations among youth in India: findings from the Youth in India: Situation and Needs study, paper presented at the XXVI International Union for the Scientific Study of Population conference, Marrakech, Morocco, Sept. 27-Oct. 2, 2009.

2. International Institute for Population Sciences (IIPS) and Population Council, Youth in India: Situation and Needs 2006-2007, Mumbai: IIPS, 2010.

3. Jejeebhoy SJ and Sebastian M, Young people's sexual and reproductive health, in: Jejeebhoy S, ed., Looking Back, Looking Forward: A Profile of Sexual and Reproductive Health in India, Jaipur, India: Rawat Publications, 2004, pp. 138-168

4. Sujay R, Premarital sexual behaviour amongst unmarried college students of Gujarat, India, Health and Population Innovation Fellowship Programme Working Paper, New Delhi: Population Council, 2009, No. 9.

5. Ganatra BR and Hirve S, Induced abortions among adolescent women in rural Maharashtra, Reproductive Health Matters, 2002, 10(19):76-85

6. Office of the Registrar General and Census Commissioner, Primary Census Abstract: Total Population Table, A-5 Series 1, New Delhi: Office of the Registrar General and Census Commissioner, 2001.

7. IIPS and Macro International, National Family Health Survey (NFHS3), 2005-06, India, Mumbai: IIPS, 2007, Vol. 1.

8. Jejeebhoy SJ et al., Spouse selection practices and gender relations within marriage among young people in Tamil Nadu: findings from the Youth in India: Situation and Needs study, paper presented at the XXVI International Union for the Scientific Study of Population conference, Marrakech, Morocco, Sept. 27-Oct. 2, 2009.
9. The Medical Termination of Pregnancy Act (No. 34), New Delhi: Government of India, 1971.

10. Drugs Controller General, India, Number of permission and date of issue MF-7059/06, 2006

11. Ganatra BR, Abortion research in India: what we know and what we need to know, in: Ramasubban R and Jejeebhoy S, eds., Women's Reproductive Health in India, Jaipur, India: Rawat Publications, 2000, pp. 186-235.

12. Dalvie SS, Second-trimester abortions in India, Reproductive Health Matters, 2008, 16(31 Suppl.):37-45.

13. Chhabra R et al., MTP and concurrent contraceptive adoption in rural India, Studies in Family Planning, 1988, 19(4):244-247.

14. Mondal A, Induced abortions in rural society and needs of people's awareness, Journal of Obstetrics and Gynecology of India, 1991, 41(4): 450-457.

15. Salvi V et al., MTPs in Indian adolescents, Journal of Obstetrics and Gynecology of India, 1991, 4l(1):33-37.

16. Solapurkar ML and Sangam RN, Has the MTP Act in India proved beneficial? Journal of Family Welfare, 1985, 31(3):46-52.

17. Aras RY, Pai NP and Jain SG, Termination of pregnancy in adolescents, Journal of Postgraduate Medicine, 1987, 33(3):120-124.

18. Purandare VN et al., A study of psycho-social factors of out-ofwedlock pregnancies, Journal of Obstetrics and Gynecology of India 1979, 29(2):303-307.

19. Divekar SA et al., Abortion in unmarried girls, Health and Population: Perspectives and Issues, 1979, 2(4):308-321.

20. Bhatt RV, An Indian study of the psychosocial behaviour of pregnant teenage women, Journal of Reproductive Medicine, 1978, 21(4): 275-278.

21. Roy Chowdhury NN and Mukherjee K, Sociological implications of pregnancy in unmarried teenagers, 1978, Journal of Obstetrics and Gynecology of India, 1979, 29(2):308-312.

22. Indian Council of Medical Research (ICMR), Collaborative Study on Short-Term Sequelae of Induced Abortion, New Delhi: ICMR, 1981.

23. Allahbadia G et al., Adolescent sexuality, pregnancy and abortion, Journal of Obstetrics and Gynecology of India, 1990, 40(2):152-155.

24. Ganguly G, Biswas A and Sharma G, Profile of women undergoing MTP in hospital, Journal of the Indian Medical Association, 1993, 91(11): 286-288.

25. Handa P, Mahajan U and Gupta I, Comparative study of the socioclinical profile of unmarried and married subjects seeking MTP: a ten year analysis, Journal of Obstetrics and Gynecology of India, 1991, 41(2): 288-291.

26. Mandal KT, Problem of unmarried mothers: a study of sociopsychological aspects of 100 women seeking MTP, Journal of the Indian Medical Association, 1982, 79(5-6):81-86.

27. IIPS and Population Council, Youth in India: Situation and Needs 2006-2007, Bihar, Mumbai: IIPS, 2009

28. IIPS and Population Council, Youth in India: Situation and Needs 2006-2007, Jharkhand, Mumbai: IIPS, 2009.

29. Ram F et al., Marriage and Motherhood: An Exploratory Study of the Social and Reproductive Health Status of Married Young Women in Gujarat and West Bengal, India, New Delhi: Population Council, 2006.

30. Jejeebhoy S and Varkey L, Maternal health and pregnancy related care, in: Jejeebhoy S, ed., Looking Back, Looking Forward: A Profile of Sexual and Reproductive Health in India, Jaipur, India: Rawat Publications, 2004, pp. 44-88.

31. Jejeebhoy S et al., Assessing Abortion-Related Experiences and Needs in Maharashtra and Rajasthan, New Delhi: Population Council, 2010. 


\section{RESUMEN}

Contexto: Se sabe poco sobre las experiencias de las mujeres jóvenes solteras en India que buscan terminar con un embarazo no planeado.

Métodos: Se condujo una encuesta entre 549 mujeres solteras de 15-24 años de edad que habian tenido un aborto en 20072008, en una de las 16 clínicas administradas por la organización no gubernamental Janani, en los estados de Bihar y Jharkhand. Se realizó la comparación entre las mujeres que tuvieron un aborto en el primer trimestre y las que lo tuvieron en el segundo trimestre, en cuanto a las diferencias en las características de sus antecedentes y en los obstáculos enfrentados para realizar un aborto; $y$, mediante análisis de regresión, se identificó la asociación entre estos factores y tener un aborto de segundo trimestre.

Resultados: El 83\% de las mujeres se percataron de su estado dentro de los primeros dos meses del embarazo y $91 \%$, dentro del los primeros tres meses. El 84\% tomaron la decisión de abortar antes del final del primer trimestre, pero solamente el $75 \%$ lo obtuvo en ese período. Una de cada seis encuestadas dijeron que el embarazo había resultado de un encuentro sexual no consensual, y tales informes fueron más frecuentes entre las que tuvieron un aborto en el segundo trimestre. Las mujeres de mayor edad o con mayor escolaridad tuvieron menores probabilidades de tener un aborto de segundo trimestre (razones de momios de 0.9, cada grupo), mientras que las que vivían en áreas rurales, que no recibieron un apoyo total de su pareja y que informaron haber tenido un encuentro forzado, tuvieron mayores probabilidades de tener un aborto tardio (2.3-4.1).

Conclusiones: Hay necesidad de programas de educación sexual para mujeres y hombres jóvenes y solteros, que destaquen la importancia de reconocer un embarazo al principio de la gestación y de realizar un aborto temprano si el embarazo no es deseado.

\section{RÉSUMÉ}

Contexte: En Inde, l'expérience des jeunes femmes non mariées qui désirent interrompre une grossesse non désirée n'est guère documentée.

Méthodes: Une enquête a été menée auprès de 549 femmes non mariées de 15 à 24 ans qui s'étaient fait avorter en 2007-2008 dans l'une de 16 cliniques gérées par l'ONG
Janani dans les états de Bihar et Jharkhand. Les différences d'antécédents et d'obstacles à l'obtention d'un avortement, entre celles qui s'étaient fait avorter durant le premier trimestre et celles qui avaient obtenu la procédure pendant le deuxième, ont été examinées. Les associations entre ces facteurs et l'obtention d'un avortement du deuxième trimestre ont été identifiées par analyse de régression logistique.

Résultats: Quatre-vingt-trois pour cent des femmes avaient pris conscience de leur grossesse durant les deux premiers mois et $91 \%$ durant le premier trimestre. Quatre-vingt-quatre pour cent avaient décidé avant la fin du premier trimestre de se faire avorter mais 75\% seulement l'avaient fait dans ce délai. Une participante sur six a déclaré que sa grossesse était le résultat d'une rencontre sexuelle non consensuelle. Ces déclarations se sont révélées plus fréquentes parmi les femmes qui s'étaient fait avorter pendant le deuxième trimestre. Les femmes plus âgées ou davantage scolarisées présentent une moindre probabilité d'avortement au deuxième trimestre (rapport de probabilités, 0,9 pour chaque groupe), tandis que celles des milieux ruraux, n'ayant pas bénéficié du plein appui de leur partenaire ou ayant déclaré un rapport forcé sont plus susceptibles d'avoir obtenu un avortement tardif $(2,3-4,1)$.

Conclusions: Il existe, pour les jeunes femmes et hommes non mariés, un besoin de programmes d'éducation sexuelle qui soulignent l'importance de la reconnaissance d'une grossesse dès le début de la gestation et celle de la prompte obtention d'un avortement si la grossesse n'est pas désirée.

\section{Acknowledgments}

This project was supported by a grant to the Population Council from the Hewlett Foundation and a grant to the Consortium for Comprehensive Abortion Care from the Packard Foundation and the Swedish International Development Agency. We are grateful to Rajib Acharya and K.G. Santhya for valuable comments and suggestions, to M.A. Jose and Komal Saxena for support in preparing the article, and to Anupa Burman, Rakhi Burman, Preeti Verma and our team of investigators for their efforts at eliciting information on these sensitive topics. The authors acknowledge input received at the IUSSP seminar Interrelationships Between Contraception, Unintended Pregnancy and Induced Abortion, held in Addis Ababa, Ethiopia, Dec. 1-3, 2008, where an earlier version of this article was presented.

Author contact: skalyanwala@popcouncil.org 